maps showing the distribution of economic species and other subjects.

The Conseil Scientifique pour l'Afrique au Sud du Sahara, and in particular Prof. Lebrun, are to be congratulated on organizing such a useful meoting, and it is to be hoped that means will be found to implement many of its recommendations.

R. W. J. KEAY

\section{NINTH INTERNATIONAL CONGRESS OF APPLIED MECHANICS}

$\mathrm{T}$

HE ninth International Congress of Applied

Mechanics was held at the Université Libre of Brussels during September 5-13. More than seven hundred members attended the Congress, and no less than five hundred communications were presented. The Congress was administered by the International Committee for Congresses of Mechanics, which is one of the organizations adhering to the International Union of Theoretical and Applied Mechanics. The president was Prof. F. van den Dungen and the secretary-general M. Jean Vandenkerckhove. A feature of the organization was the special provision which was made for young scientists, who were able to obtain cheap accommodation and meals in the Cité Universitaire, while a grant of 2,000 dollars was also available to help with their expenses of travelling to Brussels.

The main interest of the Congress naturally centred around the one-hour addresses. Mr. K. S. Davidson, of the Stevens Institute of Technology, Hoboken, N.J., gave a lecture on "Ships", in which hydrodynamics, boundary-layer theory and practical yachtsmanship were pleasantly combined. Much of the substance of this lecture is available in the Sir Geoffrey 'Taylor Memorial Volume entitled "Survoys in Mechanics" (Cambridge University Press, 1956).

Prof. R. Hill, of the University of Nottingham, gave a lecture on "New Horizons in the Mechanics of Solids". In this lecture he set up a theoretical framework sufficiently general to include problems of visco-elastic solids, including the theory of creep and work hardening.

Prof. P. Germain, of the University of Lille, lectured on "Some Recent Advances in Theoretical High Speed Aerodynamics". This was a general survey of problems of linearized supersonic theory treated by the method of the Laplace transform. Some extensions to second-order effects were also included in the lecture, which was remarkable for the speed with which it covered almost all recent developments in this subject.

Prof. H. Mettler, of the Technische Hochschule, Karlsruhe, spoke on "Forced Non-linear Vibrations of Elastic Bodies".

But perhaps the address which was most appreciated was that by Sir Geoffrey Taylor, which bore the title of "Steady Flow of Fluid entering a Region through Porous Boundaries", and which in fact dealt with the hydrodynamics of paper-making, and of painting with rollers and ordinary artists' brushes. In this extremely interesting address, Sir Geoffrey gave an account of the recent work which he has carried out to investigate the flow of the paper pulp over the rollers in paper-making machines. His investigations of roller painting and of brush painting consisted not only of simple theories embodying the main physical factors, but also of experiments which satisfactorily bore out the predictions of the theory and which were remarkable for the economy of material with which they were executed.

Apart from these general addresses, the work of the Congress was divided into two sections, the first dealing with fluid mechanies and containing some 258 papers, and the second with the mechanics of solids, containing 243 papers. In view of this great mass of material, it was necessary to limit the time available for the presentation of most papers to 15 minutes, although a certain number were givon 30 minutes. The papers were grouped in such a way that only two papers were ever being read at the same time, namely, a 30-minute paper in Section $\mathrm{I}$ and a 15-minute paper in Section II, or vice versa.

The section on fluid mechanics included papers on aerodynamics in subsonic, transonic, supersonic and hypersonic conditions, on atmospheric pollution, boundary-layer theory, hydrodynamics of waterentry problems and surface waves, lubrication, cavitation, and seepage problems in the Nile valley. A particularly interesting demonstration was given by Prof. M. Reiner, of the Israel Institute of Technology, of his centripetal pump. This machine consists of two parallel plates ground accurately flat, of which one forms the stator and the other the rotor. A pressure hole is located at the centre of the stator and the rotor is rotated at a few thousand revolutions per minute. Initially, the pressure at the centre of the stator is reduced; but as the distance between the plates is progressively reduced to a few thousandths of an inch, a pressure of several feet of water is built up.

The section on the mechanics of solids included some papers on classical problems of vibrations, on the elastic theory of plates and shells, on buckling and post-buckling problems, and on a yielding sub. soil ; but the emphasis seemed to be on plasticity, limit analysis, creep and visco-elasticity.

Mention must also be made of the social activities and of the financial support which the Congress received from Belgian banks and industries. Members of the Congress enjoyed the traditional Belgian hospitality at two receptions and a banquet. A reception was given at the University by the President, Vice-President and Rector of the Free University of Brussels and a reception at the Town Hall by M. L. Cooremans, mayor of Brussels. The banquet was held at the Hotel Metropole.

It is planned to hold the next International Congress of Applied Mechanics in 1960 in Italy.

\section{THE NUCLEI OF ATMOSPHERIC CONDENSATION}

A TMOSPHERIC aerosols cover a wide range of A particle-size from about $10^{-7} \mathrm{~cm}$. for the small ions to more than $10 \mu$ radius for the largest salt and dust particles, and a range of concentrations from less than $100 / \mathrm{cm}^{3}$ over the oceans and in the upper air to, perhaps, $10^{6} / \mathrm{cm}^{3}$ in the polluted air of large cities. Being the products of natural and man-mado combustion, of dust and spray raised from the Earth's surface, of chemical reactions taking place in the 